A family-centred occupational therapy assessment and treatment package for children with attention deficit hyperactivity disorder (ADHD) was evaluated. The package involves a multidimensional evaluation and a multifaceted intervention, which are aimed at achieving a goodness-of-fit between the child, the task demands and the environment in which the child carries out the task. The package lasts for 3 months, with 12 weekly contacts with the child, parents and teacher.

A multicentre study was carried out, with 20 occupational therapists participating. Following a 3-day training course, they implemented the package and supplied the data that they had collected from 20 children. The outcomes were assessed using the ADHD Rating Scales, pre-intervention and post-intervention. The results showed behavioural improvement in the majority of the children. The Measure of Processes of Care - 20-item version (MPOC-20) provided data on the parents' perceptions of the family-centredness of the package and also showed positive ratings.

The results offer some support for the package and the guiding model of practice, but caution should be exercised in generalising the results because of the small sample size, lack of randomisation, absence of a control group and potential experimenter effects from the research therapists. A larger-scale randomised controlled trial should be carried out to evaluate the efficacy of an improved package.

\title{
Occupational Therapy for Children with Attention Deficit Hyperactivity Disorder (ADHD), Part 2: a Multicentre Evaluation of an Assessment and Treatment Package
}

\author{
Sidney Chu ${ }^{1}$ and Frances Reynolds ${ }^{2}$
}

\section{Introduction}

In part 1 of this article, an occupational therapy model of practice for children with attention deficit hyperactivity disorder (ADHD) was described (Chu and Reynolds 2007). It addressed some specific areas of human functioning related to children with ADHD in order to guide the practice of occupational therapy. The model

${ }^{1}$ Ealing Primary Care Trust. ${ }^{2}$ Brunel University, Uxbridge, Middlesex.

Corresponding author: Dr Sidney Chu, Paediatric Occupational Therapy Service Manager, Ealing Primary Care Trust, Windmill Lodge (Ealing Hospital Site), Uxbridge Road, Southall, Middlesex UB1 3EU. Email: sidney.chu@nhs.net

Submitted: 25 May 2006.

Accepted: 13 July 2007.

Key words: Model of practice, attention deficit hyperactivity disorder, outcome study.

Reference: Chu S, Reynolds F (2007) Occupational therapy for children with attention deficit hyperactivity disorder (ADHD), part 2: a multicentre evaluation of an assessment and treatment package. British Journal of Occupational Therapy, 70(10), 439-448. provides an approach to identifying and communicating occupational performance difficulties in relation to the interaction between the child, the environment and the demands of the task. A family-centred occupational therapy assessment and treatment package based on the model was outlined. The delivery of the package was underpinned by the principles of the family-centred care approach.

Part 2 of this two-part article reports on a multicentre study, which was designed to evaluate the effectiveness and acceptability of the proposed assessment and treatment package and thereby to offer some validation of the delineation model.

It is important to note that no treatment has yet been proved to 'cure' the condition of ADHD or to produce any enduring effects in affected children once the treatment is withdrawn. So far, the only empirically validated treatments for children with ADHD with substantial research evidence are psychostimulant medication, behavioural and educational management, and combined medication and behavioural management (DuPaul and Barkley 1993, 
Jensen 1999, MTA Cooperative Group 1999). In clinical practice, it is recommended that a diagnosis of ADHD should not lead automatically to medication treatment (Taylor and Hemsley 1995), and that the first line of treatment should be educating the parents, implementing behavioural management, and using educational management with the teacher (Jouglin and Zwi 1999).

Goldstein and Goldstein (1998) noted that over the short term, a combination of treatments provides greater symptom relief and therapeutic gains than the use of any single approach. From the occupational therapy perspective, the multidimensional evaluation and the multifaceted intervention framework advocated in the model of practice described in part 1 of this article provide a systematic approach in delivering a combination of treatments. However, it is important to evaluate the effectiveness of any combined treatments proposed.

\section{Research questions}

In this study, a family-centred, occupational therapy assessment and treatment package was delivered to improve the behavioural patterns of children with ADHD aged 5-10 years. There were two principal research questions:

1. Is a defined family-centred occupational therapy assessment and treatment package carried out over 3 months effective in producing significant changes in the behavioural patterns of children with ADHD aged between 5 and 10 years?

2. Does a family-centred care approach elicit positive parental perceptions of the care that they and their children have received?

\section{Method}

\section{Research design}

In this study, the effectiveness of the package in producing significant changes in the behavioural patterns of children with ADHD was assessed using the ADHD Rating Scale - IV (DuPaul et al 1998) before and after treatment, that is, outcome evaluation. A single-group pretest-posttest design was used to evaluate change. The degree of family-centredness of the package was evaluated, using the validated Measure of Processes of Care - 20-item version (MPOC-20) (King et al 1995, King et al 1998) to measure parents' perceptions of the extent to which the health services that they and their child(ren) had received were family centred, that is, process evaluation. A single-group posttest-only design was used in this part of the study.

\section{Ethical approval of the study}

Ethical approval for this study was granted by the West Midlands Multi-Centre Research Ethics Committee (MREC), and relevant Local Research Ethics Committee (LREC) and Research Management and Governance Committee (RM\&GC) for each local researcher.

\section{Protocol of a family-centred occupational therapy assessment and treatment package}

The package was based on the principles of a family-centred care approach and the theoretical concepts described in the delineation model of occupational therapy practice for children with ADHD (see part 1 of the article, Chu and Reynolds 2007). The model recommends choosing from a number of evaluation procedures and intervention strategies, including environmental adaptation, training for parents and teachers, behavioural and educational management, the selection of appropriate tasks, and the remediation of sensory, perceptual-motor and functional difficulties. The package lasts for 3 months, with a total of 12 weekly contacts with the child, parents and teachers (Fig. 1, Chu and Reynolds 2007).

\section{Selection of local researchers}

A team of 20 paediatric occupational therapists was selected from the four countries in the United Kingdom (UK). They were part of the 72 therapists who had participated in a Consensus Development Research study on the role of occupational therapy for children with ADHD conducted by the first author (Chu 2005). The therapists who had expressed an interest in participating in this study were invited to complete an application form. The following selection criteria were used when recruiting participants:

1. Appropriate service settings, that is, those who had direct access to children with ADHD

2. Years of clinical experience (with a balance of junior and senior therapists)

3. Knowledge and skills in working with children with ADHD and related developmental problems, such as developmental coordination disorder (DCD), and their families

4. Knowledge and skills in using standardised tests

5. Experience of working within a multidisciplinary team. Although the above criteria were set, the selection process also depended on the background and number of therapists who submitted an application. As far as possible, a diversity of therapists working at different grades in the four countries of the UK was sought. A total of 24 therapists applied to participate in the study. Four applicants were eliminated because they did not have direct access to children with ADHD within their service settings. The 20 remaining therapists were asked to complete both a consent form for their participation in the study and an agreement letter for providing research data after their attendance at a free training course, which is described below.

\section{Training of local researchers on the use of the package}

The 20 therapists were invited to attend a 3-day training course in London. The course consisted of comprehensive training sessions on the research processes and each component of the assessment and treatment package (see Table 1 for details of the training programme). 
Fig. 1. Clinical pathway of the assessment and treatment package (Chu and Reynolds 2007, p380).

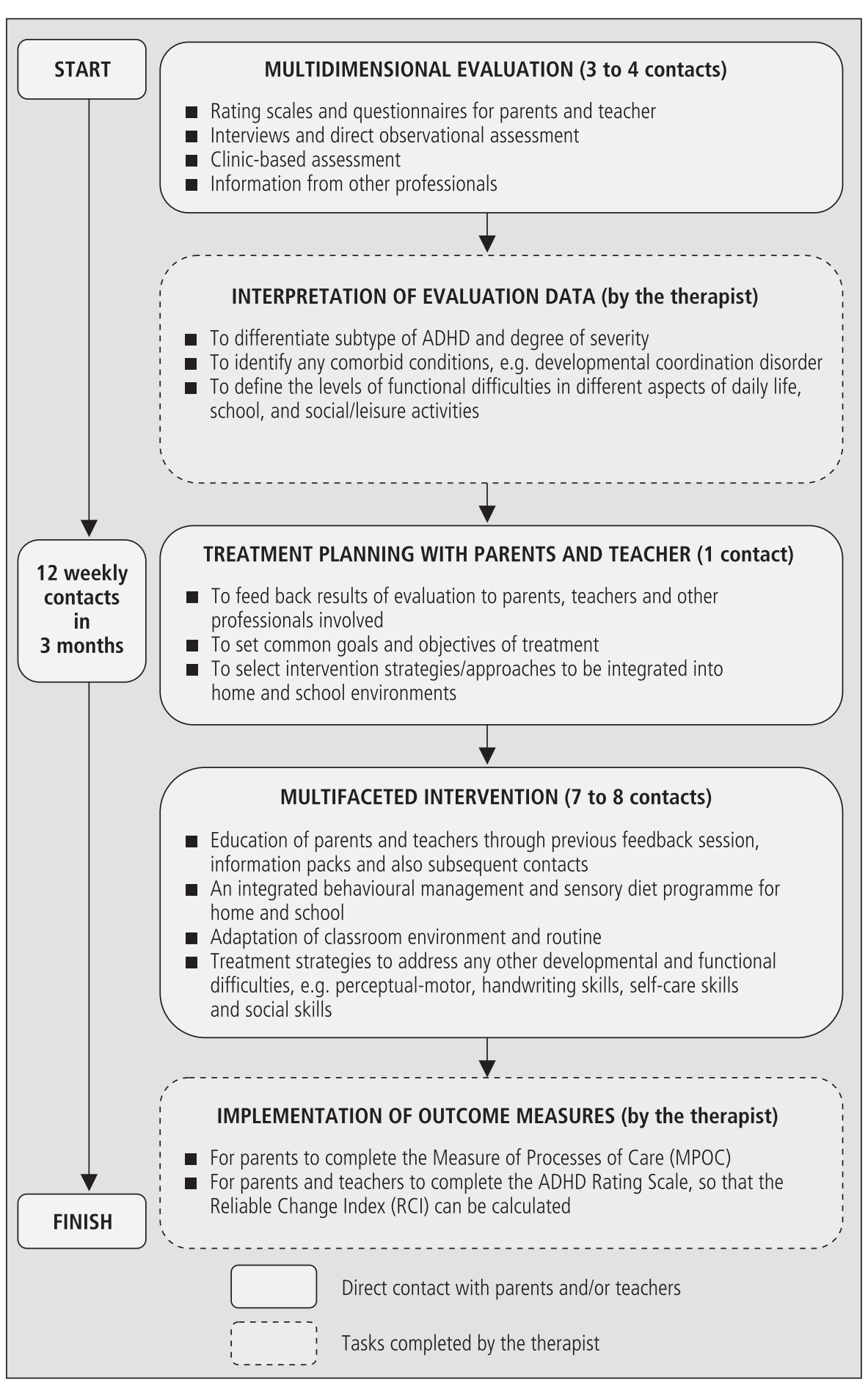

MPOC (King et al 1995, 1998); ADHD Rating Scale (DuPaul et al 1998). programme, the therapists were encouraged to select appropriate treatment procedures from the various treatment strategies covered in the training course, as appropriate to the child. Although this reduced the homogeneity of the intervention, it ensured an intervention that was more child and family appropriate yet was still compatible with the delineation model of practice.

\section{Therapists' selection of children}

Following the training, each therapist was asked to select two children who had been newly diagnosed with ADHD by a consultant child psychiatrist or consultant paediatrician who had special interest in ADHD. The child should not have been involved in any other form of treatment. The therapists used the following criteria to recruit children into the study:

1. Children aged 5 to 10 years who were referred to the service because of concerns related to ADHD

2. Children with average intellectual capacity, that is, with no identifiable learning disability

3. Children without other known neurological disorders, such as traumatic brain injury

4. Children without any other pervasive developmental disorder, including autism

5. Children without other assessed comorbid mental health problems, such as childhood schizophrenia or conduct disorder

6. Children with normal birth and delivery, that is, not children who were born preterm and with low birth weight.
The participants in the training course were given a comprehensive manual, with details of all the assessment and treatment procedures used in the research.

Attendance at the training course was free of charge in return for the submission of data.

The therapists were instructed to complete the whole package and to use the core assessment procedures outlined in the training course, except in the areas of assessing perceptual-motor and functional skills where they were permitted to use the tools adopted in their local services. In developing the multifaceted intervention

\section{Obtaining consent}

Parental consent was obtained by asking parents to sign a consent form. The parents were given an information sheet on the study so that they could make a decision on participation based on informed choice. The process of obtaining consent was based on the guidance and ethics set by the MREC, LREC and RM\&GC, such as voluntary participation and the opportunity to refuse involvement.

For the children, an information sheet in picture format was developed. Consent for Occupational Therapy (College of Occupational Therapists 2003, section 4.2) 
Table 1. Contents of the 3-day training programme

1. Details of the research protocol (including the research questions, research design, selection of subjects, obtaining consent, coding system for data protection and data collection for outcome measures)

2. An overview of the assessment protocol

3. Principles of family-centred approach

4. The Measure of Processes of Care (MPOC)

5. DSM-IV Diagnostic Criteria of ADHD

6. ADHD Rating Scale - administration, scoring and interpretation

7. Sensory Profile - administration, scoring and interpretation

8. Interview with parents, teachers and the child

9. Observational assessment within school environment

10. Other assessment areas and tools, such as perceptual-motor and functional skills

11. Overall interpretation of assessment results

12. Report writing and case examples

13. An overview of the treatment protocol

14. Feedback session with parents and teachers

15. Goal setting and treatment planning with parents and teachers

16. Psychoeducational packs for parents and teachers

17. Behavioural management

18. The application of principles of sensory modulation and intervention strategies in the treatment of children with ADHD

19. Classroom management and environmental adaptation

20. Appendices - all the assessment forms, consent information and forms, psychoeducational packs and treatment programmes.

and Seeking Consent: Working with Children (Department of Health 2001) were used to guide therapists in gaining assent from the children. For the child's general practitioner and teacher, information sheets were developed about the purpose of the research project.

\section{Procedures of data collection and the coding system for data protection}

In order to ensure the reliability and validity of the data collected, the chief investigator (the first author) had maintained regular communication with the 20 therapists. He provided advice and consultation to each therapist on the implementation of the research processes and different aspects of the package. All therapists were requested to send to the chief investigator details of the assessment results, interpretation of the multidimensional evaluation, goals and objectives set, and treatment programmes with all procedures selected. If there were any anomalies identified, such as incorrect scoring of assessment tools or missing data, the chief investigator queried these as soon as possible.

In order to adhere to the Data Protection Act, a coding system was used to ensure that the families and children could not be identified. The allocated codes were used in all the forms and documentations sent to the chief investigator. All data were kept securely.

\section{Outcome measures and method of data analysis}

After the implementation of the package, two outcome measures were used in collecting data for the outcome and process evaluation of the package.

For the outcome evaluation, the Reliable Change Index (RCI) for each child was calculated by comparing the scores of the ADHD Rating Scale - IV Home and School Versions (DuPaul et al 1998) before and after treatment. According to Jacobsen and Truax (1991, cited in DuPaul et al 1998), the RCI is equal to the difference between a child's pretreatment score and posttreatment score, divided by the standard error of difference between the two test scores. In the manual of the ADHD Rating Scale - IV (DuPaul et al 1998), two tables of the standard errors of difference for the School Version and the Home Version are available for calculating the RCI. When the value of RCI exceeds 1.96, it indicates that the change from pretreatment to posttreatment is not due to chance $(p<0.05)$. Thus, the RCI serves as a measure of the degree to which an improvement in functioning is likely to be due to the effects of treatment rather than to imprecise measurement.

For the process evaluation, the descriptive statistics for the MPOC were used to analyse the extent to which the parents perceived the intervention to have been family centred. The original version of the MPOC is a 56-item questionnaire. As of 1998, there is a shorter, 20-item version (King et al 1998). The validity evidence shows that the MPOC-20 can capture parents' perceptions of care-giving regardless of the child's diagnosis or age (King et al 2004).

The MPOC contains five scales: (1) Enabling and Partnership, (2) Providing General Information, (3) Providing Specific Information about the Child, (4) Coordinated and Comprehensive Care for the Child and Family, and (5) Respectful and Supportive Care. The data from a respondent yield five scores, one for each of the scales. There is no total score because it is thought to be more informative clinically to examine the relationships of the individual scales to other variables (King et al 1995).

\section{Results}

\section{Characteristics of therapists participating in the study}

The demographic data for the 20 therapists who participated in the study were as follows. There were 11 therapists from England, 4 from Scotland, 2 from Wales and 3 from Northern Ireland. Eleven therapists were working at senior I grade. There was 1 therapist at senior II grade, 3 at clinical specialist grade, 4 at head III grade and 1 senior therapist in independent practice for a local primary care trust. Thirteen of these therapists worked in a child health setting within the community. There were 7 therapists who worked in a child psychiatry setting in England and Scotland but none in Wales and Northern Ireland. The therapists' years of working experience in all clinical areas of occupational therapy ranged from 6 to 34 years, with 
Table 2. Clinical characteristics of the 20 children

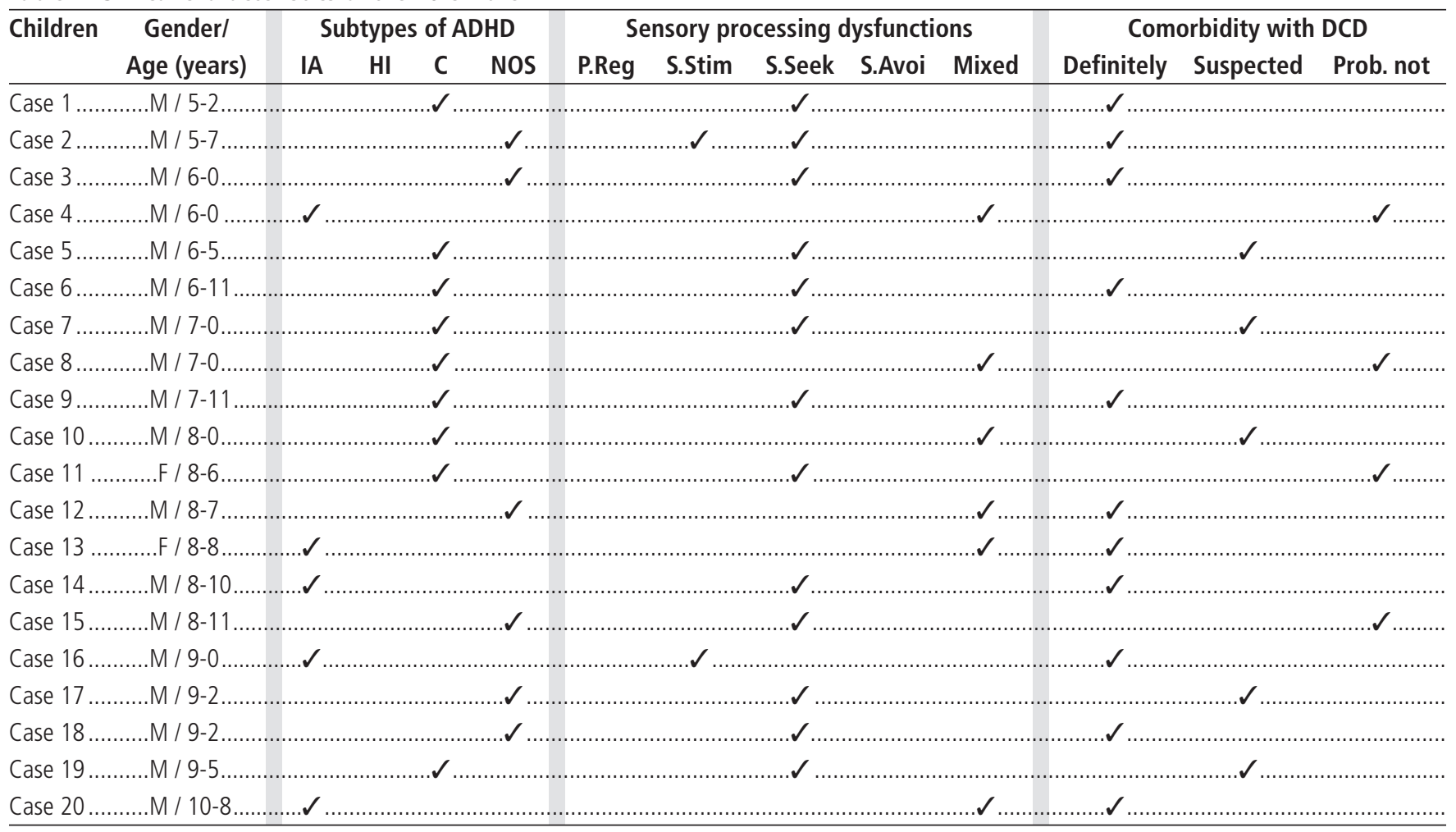

IA = ADHD Inattentive Type, HI = ADHD Hyperactive-Impulsive Type, C = ADHD Combined Type, NOS = ADHD Not Otherwise Specified.

P.Reg = Poor Registration, S.Stim = Sensitivity to Stimuli, S.Seek = Sensory Seeking, S.Avoi = Sensory Avoidance, Mixed = Mixed Patterns.

DCD = Developmental coordination disorder.

a mean of 17.7 years and a standard deviation of 8.5 .

Their experience of working with children ranged from 2.5 to 34 years, with a mean of 12.6 years and a standard deviation of 8.9 .

\section{Number and demographic characteristics of the children}

Although 40 cases were sought, data were returned on 20 children due to various reasons, such as the non-availability of children matching the selection criteria and incomplete data because of families moving away. There were 18 boys and 2 girls. The mean age for the 18 boys was 91.3 months ( 7 years 7.3 months), with a range of 62 months ( 5 years 2 months) to 128 months (10 years 8 months). The mean age for the two girls was 103 months ( 8 years 7 months), with actual ages of 8 years 6 months and 8 years 8 months.

\section{Clinical characteristics of the $\mathbf{2 0}$ children}

The clinical characteristics of each child are presented in Table 2. The children were arranged in the order of their chronological ages. All children were assessed by using the range of evaluation procedures and assessment tools specified in the package (see Table 1). The information obtained enabled the therapists to differentiate subtypes of ADHD, identify underlying sensory processing dysfunctions, evaluate the degree of comorbidity with DCD and plan the treatment programme by selecting appropriate components within the multifaceted intervention model described.
Although these data will not be used for measuring the outcomes of the package, they are useful in analysing the specificity of each case. The children's clinical characteristics are presented in the following areas. The representativeness of the sample will be returned to in the discussion.

1. The subtypes of ADHD were identified. These were based on the results of the ADHD Rating Scales and other assessment procedures administered by the research therapists, such as classroom observation. The subtypes included (American Psychiatric Association 1994):

a. ADHD Predominantly Inattentive Type (ADHD-IA)

b. ADHD Predominantly Hyperactive-Impulsive Type (ADHD-HI)

c. ADHD Combined Type (ADHD-C)

d. ADHD Not Otherwise Specified (ADHD NOS).

2. The types of sensory processing dysfunction that were present in the sample were based on the categories described in the Sensory Profile (Dunn 1999). A child could have behavioural features related to one or more of the categories below:

a. Poor Registration - uninterested, dull affect, withdrawn, overly tired, apathetic and self-absorbed

b. Sensitivity to Stimuli - distractible and hyperactive

c. Sensation Seeking - active, fidgety and excitable

d. Sensation Avoiding - resistant to change and reliant on rigid rituals

e. Mixed Patterns - presents a mixture of behavioural features related to more than one category. 
Table 3. Outcomes of the ADHD Rating Scale - Home and School Versions

\begin{tabular}{|c|c|c|c|c|c|}
\hline \multirow{2}{*}{$\begin{array}{l}\text { Children } \\
\text { Gender, CA }\end{array}$} & \multirow[t]{2}{*}{ Version } & Pretreatment scores & Posttreatment scores & SED & $\mathrm{RCl}$ \\
\hline & & IA $\quad$ HI Total & IA $\quad$ HI $\quad$ Total & Total & Total \\
\hline Case $1 \ldots \ldots \ldots . . .$. & ..Home. & $.21 \ldots$ & $. .15 .$. & .2 .94 & $.2 .04^{*}$ \\
\hline$M, 5-2 \ldots$ & ...School.. & 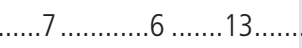 & $\ldots 3 \ldots . . . . .9$. & $\ldots 3.85 \ldots \ldots .6 .53$ & $\ldots 0.28 \ldots \ldots . .0 .78 \ldots \ldots \ldots .61 \ldots$ \\
\hline & ...Home. & ...24 .......49. & ...20_........39.. & $. .3 .37 \ldots \ldots . .2 .94 \ldots \ldots .5 .46$. & $\ldots 1.78 \ldots \ldots . .1 .36 \ldots \ldots \ldots 1.83 \ldots \ldots$ \\
\hline M, 5-7. & ...School. & $\ldots 27 \ldots \ldots .52 .$. & $\ldots 16 \ldots \ldots . . .31 .$. &. $.59 \ldots \ldots .3 .85 \ldots \ldots .6 .53$. & $.2 .79 * \ldots .2 .86 * \ldots \ldots .22 * \ldots$ \\
\hline Case $3 .$. & ...Home. & $\ldots 26 \ldots . . .47 .$. & $\ldots 14 \ldots \ldots .22 \ldots \ldots \ldots .36$. & $\ldots 2.94 \ldots \ldots . .5 .46$ & $.2 .08 * \ldots . .1 .36 \ldots \ldots$ \\
\hline & ...School. & $\ldots .26 \ldots \ldots .44$... & (2) &. $.3 .59 \ldots \ldots .3 .85 \ldots \ldots .6 .53$. & (n) \\
\hline & & $\ldots .17 \ldots . . .34$... & $\ldots 23 \ldots \ldots . . .46$. & $\ldots 2.94 \ldots \ldots . .5 .46$ & $-1.78 \ldots \ldots-2.04 \ldots \ldots .-2.20 \ldots$ \\
\hline & ...School. & $\ldots 17 \ldots$ & $\ldots 20 \ldots$ & $\ldots .85 \ldots \ldots .6 .53$ & $\ldots 0.56 \ldots \ldots .-0.78 \ldots \ldots \ldots-0$ \\
\hline & & $\ldots .25 \ldots \ldots .47 .$. & $\ldots 16 \ldots$ & ....2.94 _.......5.46 . & $\ldots 1.78 \ldots \ldots .4 .08 * \ldots \ldots 3.30 * \ldots$ \\
\hline & ...School. & $\ldots .9 \ldots \ldots \ldots 11 \ldots \ldots . . .20$. & $\ldots . .9 \ldots \ldots . .16$ & ...3.59 _.......3.85 _......6.53 . & $\ldots 0.56 \ldots \ldots .0 .52 \ldots \ldots \ldots .0 .61 \ldots \ldots$ \\
\hline & ... Ho & $\ldots .24 \ldots \ldots .45 .$. & $\ldots 15 \ldots \ldots \ldots . .26$ & $.3 .37 \ldots \ldots .2 .94 \ldots \ldots .5 .46$. & $.2 .97^{*} \ldots .3 .06^{*} \ldots \ldots .3 .48^{*} \ldots$ \\
\hline & ...sch & $\ldots . .23 \ldots \ldots .44$. & 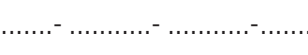 &. $.3 .59 \ldots \ldots .3 .85 \ldots \ldots .6 .53$ & 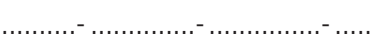 \\
\hline & ...Ho & $\ldots 20 \ldots$ & $\ldots 20 \ldots$ & ...3.37 _......2.94 _.....5.46 & $\ldots 0.00 \ldots \ldots .0 .00 \ldots \ldots . .0 .00 \ldots$. \\
\hline & ...School. & $\ldots .18 \ldots . .33 .$. & $\ldots .17 \ldots$ & 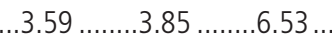 & $\ldots-0.56 \ldots \ldots .2 .60 * \ldots \ldots .1 .23 \ldots$. \\
\hline 8 & ...Hom & $\ldots .25 \ldots . .39 .$. & $\ldots 13 \ldots \ldots .20 \ldots \ldots \ldots . .33 .$. & $\ldots .37 \ldots . . . .2 .94 \ldots \ldots . .46$. & $\ldots 0.30 \ldots \ldots .1 .70 \ldots \ldots . .1 .20 \ldots$ \\
\hline IVI, /-O ... & ...School. & ...20 .........20 ......40.. & $\ldots 20 \ldots \ldots .20 \ldots \ldots \ldots .40$. & ...3.59 _.......3.85 _.......6.53. & $\ldots .0 .00 \ldots \ldots .0 .00 \ldots \ldots . .0 .00 \ldots$ \\
\hline Case 9. & ..Home. & $\ldots 26 \ldots \ldots \ldots . .26 \ldots \ldots .52 .$. & $\ldots .19 \ldots \ldots .17 \ldots \ldots . .36 .$. & 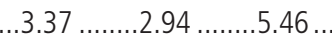 & $\ldots 2.08 * \ldots .3 .06 * \ldots \ldots .2 .93 * \ldots$ \\
\hline$M, 1-11 \ldots$ & ...School. & $\ldots 25 \ldots \ldots \ldots .21 \ldots \ldots .46 .$. & $\ldots .22 \ldots \ldots \ldots 19 \ldots \ldots \ldots 41$. & $. .59 \ldots \ldots .35 \ldots . .35$ & $\ldots .0 .84 \ldots \ldots . .0 .52 \ldots \ldots \ldots .0 .77 \ldots \ldots$ \\
\hline Case 10. & ...Home. & $\ldots . .21 \ldots . .39 .$. & $\ldots 14 \ldots \ldots . .20 \ldots \ldots . .34 .$. & ...3.54 _......2.77 _......5.37 . & $\ldots 1.13 \ldots \ldots .0 .36 \ldots \ldots \ldots .0 .93 \ldots \ldots$ \\
\hline$M, 8$ & ...School. & $\ldots 24 \ldots \ldots \ldots .23 \ldots \ldots .47 .$. & $\ldots .21 \ldots \ldots . .21 \ldots \ldots \ldots .42 .$. & ...3.99 …....3.95 _......6.9 & $\ldots 0.75 \ldots \ldots .0 .51 \ldots \ldots \ldots .0 .72 \ldots \ldots$ \\
\hline Case $11 \ldots$ & ...Home.. & $\ldots 21 \ldots \ldots \ldots .22 \ldots \ldots .43 \ldots$ & $\ldots 18 \ldots \ldots .16 \ldots \ldots .34 \ldots$ & 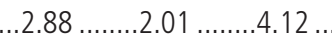 & $\ldots 1.04 \ldots \ldots .2 .99 * \ldots \ldots .2 .18^{*} \ldots$ \\
\hline & ...Sch & $\ldots 26 \ldots \ldots \ldots .27 \ldots \ldots .53 .$. & $\ldots .20 \ldots \ldots \ldots 18 \ldots \ldots \ldots 38$. & $\ldots 3.42 \ldots \ldots .3 .01 \ldots \ldots .5 .64$ & $\ldots 1.75 \ldots \ldots .2 .99 * \ldots \ldots .2 .66^{*} \ldots$ \\
\hline 12 & Home & $\ldots 24 \ldots \ldots \ldots .14 \ldots \ldots 38 \ldots$ & $\ldots .19 \ldots \ldots .13 \ldots \ldots \ldots . .32$. & ...3.54 „.......2.77 _......5.37 . & $\ldots .41 \ldots \ldots .0 .36 \ldots \ldots \ldots .12 \ldots \ldots$ \\
\hline & ...Sch & $\ldots 17 .$. & $\ldots .14 \ldots \ldots \ldots .28$ & $\ldots .3 .95$ & $\ldots \ldots . .0 .87 \ldots$ \\
\hline Case 13. & ...Home.... & $\ldots 24 \ldots \ldots \ldots .12 \ldots \ldots . .36 \ldots$ & $\ldots .14 \ldots \ldots \ldots 13 \ldots \ldots \ldots .27 \ldots$ & $\ldots 2.88 \ldots \ldots .2 .01 \ldots \ldots .4 .12 \ldots$ & $\ldots 3.47 * \ldots .-0.50 \ldots \ldots .2 .18 * \ldots$ \\
\hline & ...School... & $\ldots 17 \ldots \ldots \ldots .12 \ldots \ldots .29 \ldots$ & $\ldots .12 \ldots \ldots \ldots . .99 \ldots \ldots .21 .$. & $\ldots 3.42 \ldots \ldots .3 .01 \ldots \ldots .5 .64$ & $\ldots .1 .46 \ldots \ldots .1 .00 \ldots \ldots \ldots .1 .42 \ldots \ldots$ \\
\hline & ...Home.... & 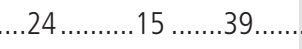 & $\ldots .18 \ldots \ldots . .15 \ldots \ldots \ldots 33 \ldots$ & 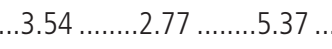 & $\ldots .1 .70 \ldots \ldots . .0 .00 \ldots \ldots \ldots .1 .12 \ldots \ldots$ \\
\hline & ...School... & $\ldots 19 \ldots \ldots \ldots .16 \ldots \ldots .35 \ldots$ & $\ldots . .9 \ldots \ldots \ldots .8 \ldots \ldots \ldots 17 .$. & ...3.99 _......3.95 _......6.93. & $\ldots .2 .51 * \ldots .2 .03 * \ldots \ldots .2 .60 * \ldots$ \\
\hline & Hom & $\ldots 18 \ldots \ldots \ldots .18 \ldots \ldots . .36 \ldots$ & $\ldots .20 \ldots \ldots . .18 \ldots \ldots . .38$.. & 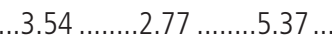 & $\ldots-0.56 \ldots \ldots .0 .00 \ldots \ldots . .0 .37 \ldots \ldots$ \\
\hline & $\ldots$ Sch & ...15 ..........2 .....17... & $\ldots .20 \ldots \ldots \ldots \ldots .2 \ldots \ldots .22 .$. & ...3.99 _........3.95 …...6. & $0 \cap 0=0$ \\
\hline & ...Home... & 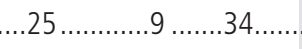 & $\ldots .8 \ldots \ldots \ldots \ldots \ldots \ldots \ldots \ldots$ & 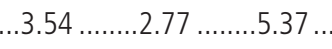 & $\ldots .4 .80 * \ldots . .1 .08 \ldots \ldots .3 .72 * \ldots$ \\
\hline & ...School... & $\ldots 24 \ldots \ldots \ldots .14 \ldots \ldots 38 \ldots$ & $\ldots .16 \ldots \ldots \ldots \ldots \ldots \ldots \ldots$ & ...99 _......3.95 _.....6.93 ... & $\ldots 2.01 * \ldots .2 .28 * \ldots \ldots .2 .45^{*} \ldots$ \\
\hline & ...Home.... & $\ldots 26 \ldots \ldots \ldots . .27 \ldots \ldots .53 \ldots$. & $\ldots .7 \ldots \ldots \ldots . .7 \ldots \ldots \ldots .14 \ldots$ & 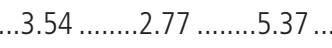 & $\ldots .5 .37 * \ldots . .7 .22 * \ldots \ldots .7 .26 * \ldots$ \\
\hline & ...School.. & 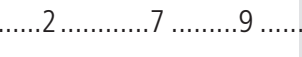 & & $. .99 \ldots . . .3 .95 \ldots \ldots .93$ & 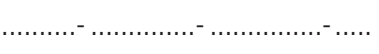 \\
\hline & ...Home..... & $\ldots 25 \ldots \ldots \ldots .22 \ldots \ldots .47 \ldots$. & $\ldots 24 \ldots \ldots \ldots .24 \ldots \ldots \ldots .48 \ldots$ & 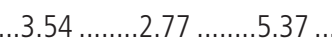 & $\ldots 0.28 \ldots \ldots-0.72 \ldots \ldots \ldots-0.19 \ldots \ldots$ \\
\hline & ...School... & $\ldots 14 \ldots \ldots \ldots .21 \ldots \ldots . . .35 \ldots \ldots$ & $\ldots 16 \ldots \ldots \ldots .20 \ldots \ldots \ldots .36 \ldots$ & $. . .99 \ldots \ldots .3 .95 \ldots \ldots .6 .93 .$. & $\ldots-0.50 \ldots \ldots .0 .25 \ldots \ldots . .0 .14 \ldots \ldots$ \\
\hline & & $\ldots 27 \ldots \ldots \ldots .26 \ldots \ldots .53 \ldots$ & $\ldots 24 \ldots \ldots \ldots 21 \ldots \ldots . .45 \ldots$ & $. .3 .54 \ldots \ldots .2 .77 \ldots \ldots . .5 .37$ & $\ldots .0 .85 \ldots \ldots .1 .81 \ldots \ldots .1 .15 \ldots$ \\
\hline & ...School... & $\ldots 20 \ldots \ldots \ldots .23 \ldots \ldots . . .43 \ldots \ldots$ & $\ldots .19 \ldots \ldots \ldots 19 \ldots \ldots \ldots .38 \ldots$ & ...3.99 _......3.95 _......6.93 & $\ldots .0 .25 \ldots \ldots . .1 .01 \ldots \ldots \ldots .0 .72 \ldots \ldots$ \\
\hline & ...Home..... & $\ldots 19 \ldots \ldots \ldots .14 \ldots \ldots .33 \ldots \ldots$ & $\ldots 13 \ldots \ldots \ldots .9 . \ldots \ldots \ldots .22 \ldots$. & $\ldots 3.54 \ldots \ldots . .2 .77 \ldots \ldots . . .5 .37 \ldots$ & $\ldots .1 .70 \ldots \ldots .1 .81 \ldots \ldots .2 .05^{*} \ldots$ \\
\hline & &. $.20 \ldots \ldots \ldots \ldots .7 \ldots \ldots .27 \ldots$ & $\ldots 12 \ldots \ldots \ldots 3 \ldots \ldots \ldots \ldots$ & ...99 _.......3.95 _.......6.93 .. & $\ldots 2.01 * \ldots . .1 .01 \ldots \ldots .1 .73 \ldots$ \\
\hline
\end{tabular}

$C A=$ Chronological age; $I A=$ Inattention Subscale, $\mathrm{HI}=$ Hyperactivity-Impulsivity Subscale; ${ }^{*}=$ Level of significance $(p<0.05) ;$ SED $=$ Standard errors of difference (figures from test manual); $\mathrm{RCl}=$ Reliable Change Index.

Table 4. Descriptive statistics for the Measure of Processes of Care (MPOC-20)

\begin{tabular}{|c|c|c|c|c|c|c|c|}
\hline \multirow[t]{2}{*}{ Scale name } & \multirow{2}{*}{$\begin{array}{c}\text { Mean } \\
\text { (M) }\end{array}$} & \multirow{2}{*}{$\begin{array}{l}\text { Scores within } \\
\qquad M \pm S D\end{array}$} & \multirow[t]{2}{*}{ Min. Max. Range } & \multirow[t]{2}{*}{ Mode Median } & \multicolumn{3}{|c|}{ Quartiles } \\
\hline & & & & & $25 \%$ & $50 \%$ & $75 \%$ \\
\hline Enablir & $\ldots 6.23 \ldots .1 .02 .$. & $\ldots .5 .21$ to $7.25 \ldots$ & $\ldots . .7 \ldots$ & ...7 $7 \ldots \ldots .6 .67$. & $.6 .00 .$. & $. .6 .67 .$. & $\ldots 6.92 \ldots$ \\
\hline Providing $C$ & $. .6 .67 \ldots 1.42 .$. & ....4.25 to $7.09 .$. & $\ldots .2 \ldots \ldots \ldots .7 \ldots \ldots \ldots .5$ & $\ldots .66^{*} \ldots \ldots .6$. & $\ldots 5.05$. & &. $.6 .75 \ldots$ \\
\hline $\begin{array}{l}\text { Providing Specific Information } \\
\text { about the Child }\end{array}$ & $\ldots 6.3$ &. .5 .39 to $7.35 .$. & $\ldots 5 \ldots$ & $\ldots 7 \ldots$ & ...6.08.. & 667 & $\ldots 7.00 \ldots$ \\
\hline Coordinated and Comprehensive Care. & $\ldots 6.48 \ldots 0.78$.. & $\ldots .70$ to $7.26 \ldots$ & $\ldots .3 \ldots \ldots \ldots .7 \ldots \ldots \ldots . .4 \ldots$ & $\ldots .7 \ldots \ldots \ldots .69 \ldots$ & ...6.00.. & ..6.89... & $\ldots 7.00 \ldots$ \\
\hline Respectful and Supportive Care.... &. $.6 .42 \ldots 0.70$. & $\ldots .72$ to 7.12 ... & $\ldots .4 \ldots \ldots .7 \ldots \ldots \ldots 3 \ldots$ & $\ldots .7 \ldots \ldots .6 .80 \ldots$ & $\ldots 5.75 .$. & $\ldots 6.80 \ldots$ & $\ldots 6.95 \ldots$ \\
\hline
\end{tabular}

$\mathrm{M}=$ Mean, SD = Standard deviation, Min. = Minimum, Max. = Maximum, ${ }^{*}$ More than one mode (6 and 7), the lower value being reported. 
3. The absence or presence of $D C D$ was identified in each child. Categorisation was based on the results of different perceptual and motor tests administered by the research therapists. The degree of DCD was described as follows:

a. Definitely an indication of DCD

b. Suspected of having DCD

c. Probably not DCD.

\section{Outcomes of the ADHD Rating Scales}

The scores for both the Home and School Versions of the ADHD Rating Scales were obtained before and after the completion of the package, except in three cases where no scores were obtained for the posttreatment School Version of the ADHD Rating Scale owing to the commencement of the summer holiday. The RCI for each child was calculated and is presented in Table 3. As stated, if the value of the RCI exceeds 1.96 , it indicates that the change from pretreatment to posttreatment is due not to chance $(\mathrm{p}<0.05)$ but to the effectiveness of the care package.

Overall, 17 children showed an improvement in the scores before and after treatment, and 3 children showed a slight deterioration in the scores after treatment. Thirteen children showed statistically significant changes in scores in at least one of the subscales, and 11 children showed statistically significant changes in scores in either one or both of the total scales in the whole ADHD Rating Scales.

\section{Outcomes of the MPOC-20}

The descriptive statistics for the five scales of the MPOC-20 are reported in Table 4. In the MPOC manual, the use of mean, standard deviation (SD) and range of scores is recommended to analyse the data (King et al 1995). A mean score around 4 indicates that, on average, parents report that the service 'sometimes' meets their needs on that scale, and a mean score of 7 (or just slightly less than 7) indicates that needs are being met 'to a great extent'. In addition to these descriptions for certain mean values, the mean plus the standard deviation and the range of scores provided useful information about how much variability or dispersion there was in the data set.

The highest mean score (6.48) obtained was in the scale of 'Coordinated and Comprehensive Care', while the lowest mean score (5.67) was in the scale of 'Providing General Information'. Overall, the mean scores for all the five scales were higher than the score of 4 . In examining the scores within -1 SD and +1 SD, most of the scores were above 5, with only the scale 'Providing General Information' having a lower score at 4.25. For the range of scores from minimum to maximum, only two parents gave low scores of 2 and 3. The overall results indicated that the parents experienced good levels of family-centred care, as delivered by the research therapists when they were implementing the package.

In view of the recommendation for analysing ordinal data based on a Likert scale (for example, Giles 2002), other descriptive statistics (that is, mode, median and quartiles) were also used to analyse the data. The findings were similar. As indicated in Table 4, the mode for the five scales was 7 , that is, 'to a great extent', with the exception of the scale 'Providing General Information', which had two values of mode at 6 and 7 . The medians for the five scales were all at and above 6 . They were consistent with the mean values calculated for each scale. The interquartile range was 5-7.

\section{Discussion}

\section{Demographic characteristics of the 20 therapists}

As reported, the occupational therapists were selected from the four countries, with England having the higher number because of the larger population size. There was a good mix of therapists working at different grades and in different service settings. A majority of the therapists had considerable clinical experience in working with children, with the mean years of experience being 12.6. Although the grade, work setting and years of experience of the research therapists were not considered in the process and outcome evaluations, these factors could have enhanced the effectiveness of the package.

\section{Demographic and clinical characteristics of the $\mathbf{2 0}$ children}

The higher ratio of boys to girls in this study reflects clinical populations (American Psychiatric Association 1994, Gomez et al 1999, National Institute for Clinical Excellence 2000). Girls with ADHD are less prevalent and usually present with the Inattentive Type (Carlson et al 1999, Milich et al 2001). Of the two girls (cases 11 and 13) in this study, one was identified as having the Inattentive Type.

With regard to the whole cohort of 20 children, five children (cases 4, 13, 14, 16 and 20) were identified as having the Inattentive Type. This is relatively unusual because such children are not usually identified and referred to a clinical service until a later stage in their education (Wodrich 1994). Children with the Inattentive Type have a different behavioural pattern from that of children with the Hyperactive-Impulsive Type and the Combined Type. There is a view that the Inattentive Type might have different aetiological factors and be a separate disorder (Carlson et al 1999). In examining the types of sensory processing dysfunction in these five children, four did not have the typical Sensory Seeking pattern identified in children with ADHD (Dunn 1999, Dunn and Bennett 2002). They presented either a Mixed Pattern or a pattern opposite to the Sensory Seeking pattern, that is, the Sensitivity to Stimuli pattern. Tentatively, the clinical characteristics of these five children did support the argument that children with the Inattentive Type do have different underlying dysfunctions. Therefore, it is important to assess their underlying neurological functions in order to decide on the choice of treatment approaches. This finding further reinforced the importance of adopting the multidimensional evaluation procedures advocated in the model of practice. 
Of the other 15 children, most had the Combined Type, which is the most common subtype of ADHD referred to a clinical service. Six children were classified as ADHD Not Otherwise Specified (NOS) because they did present features of ADHD but did not completely meet the diagnostic criteria. A majority of the children presented with the Sensory Seeking pattern commonly identified in children with ADHD. This is consistent with the research findings of Mangeot et al (2001) and Dunn and Bennett (2002). These data supported the use of sensory integrative treatment techniques as part of the multifaceted treatment programme.

Over half of the children in this study presented comorbidity with DCD. This is consistent with the research findings by Gillberg and Kadesjo (2000) that the prevalence of comorbid ADHD and DCD is as high as $50 \%$. These data supported the importance of assessing other developmental skills as part of the multidimensional evaluation model, since many children with ADHD referred to a clinical service additionally present problems in either gross motor skills or fine motor skills, or both (Whitmont and Clark 1996, Harvey and Reid 1997, Piek et al 1999, Christiansen 2000, Johnson and Rosen 2000, Pitcher et al 2003, Tseng et al 2004).

The clinical characteristics of these 20 children, as identified above, had consistent links to previous research findings of children with ADHD. This suggested that the study used a reasonably representative sample.

\section{Efficacy of the package as measured by the ADHD Rating Scales}

One of the unique features of the package was the combination of intervention strategies at the child, task and environment levels, chosen flexibly to suit the child and family. It was aimed at empowering parents and teachers to manage the child's behaviours by using different treatment strategies, which hopefully should be more long lasting than medication. Another unique feature was the family-centred care approach in service delivery. It made the whole package one coherent entity that was very different from other available combined treatment methods.

Even though it was implemented in a relatively short timescale, a majority of the children showed improvement in the scores after the implementation of the package, as measured by the posttreatment ADHD Rating Scales. Over half of the children had significant changes in scores (as indicated by the value of the RCI in Table 3) in at least one of the subscales or in one or both of the total scales of the ADHD Rating Scales. It was interesting to note that the most significant changes in scores were related to the Home Version of the ADHD Rating Scale. This could be related to the family-centredness of the care package or to the fact that it was more difficult for teachers to make changes within the school environment within such a short timescale.

In view of the short duration of the treatment component of the package (that is, 7 to 8 contacts within 2 months after the multidimensional evaluation), the results were encouraging and comparable to other efficacy studies using different forms of treatments (MTA Cooperative Group 1999, Klein et al 2004). The results of this multicentre study could provide a stepping stone to developing a form of intervention to replace or reduce the use of medication treatment, which mainly provides temporary relief of the signs and symptoms of ADHD. It is important to note that the average positive response rate in using medication as a single treatment modality has been found to be 70\% (Spencer et al 1996). Yet once the effect of medication subsides, the child will return to his or her original behavioural state. Therefore, other forms of treatment that could have a long-lasting effect should be explored. This package enables parents to use different behavioural and sensory modulation techniques, teaches the children different coping strategies, and empowers teachers to adapt the learning environment and to select appropriate tasks for a child with ADHD.

Three children (cases 4, 15 and 18) showed some deterioration in their scores after the treatment. The decline in behavioural functioning could be coincidental. Alternatively, there may have been specific factors related to the therapist in the implementation of the package (for example, years of clinical experience). However, the sample in this study is too small for the matter to be resolved satisfactorily. For further research regarding the package, it might be helpful to explore factors related to the efficacy of the research therapists, such as the effect of the years of clinical experience of the therapists, the range of postgraduate training completed and the service setting in which they work.

\section{The degree of family-centredness in the delivery of the package as measured by the MPOC-20}

Shelton et al (1987) highlighted that parent-therapist collaboration was central to family-centred care, with both offering different perspectives and sources of expertise. Although therapists can offer the expertise of their skills and knowledge gained from working with a number of children, parents are the only ones who can contribute information about their particular child in all settings. Parent-therapist collaboration can lead to more comprehensive and more appropriate treatment plans, which are individually tailored to both the child's and family's strengths and needs.

The positive results of the MPOC-20 supported the importance of parent-therapist collaboration, since most parents reported gains in confidence in managing their children with ADHD. The only weaker score was in the scale of 'Providing General Information'. This could be improved in future interventions by (a) providing more opportunities for the entire family to obtain information; (b) having information available in various forms, such as booklet, kit and video; and (c) providing more advice on how to get information or to contact other parents. 
Although the MPOC-20 was used as an outcome measure in this study, the MPOC-56 is a tool that is still particularly useful for research and a more in-depth assessment. The additional content of the MPOC-56, which has more items within each scale, provides more concrete ideas for improvement. For any further larger-scale study, the MPOC-56 is recommended.

\section{Limitations of the study}

Although positive results were achieved in this study, caution should be exercised in generalising the results, given the small sample size, the lack of randomisation in the selection of participants and the absence of a control group. There might also have been experimenter effects on the part of the research therapists in collecting the data, since they might have been particularly enthusiastic following the training days. This eventuality could be minimised by having a therapist who implements the package and a separate person who collects the data. A further larger-scale study needs to be carried out using a randomised controlled trial.

Although the research therapists were instructed to complete the whole package, no formal procedure was undertaken to ascertain the fidelity to treatment, which refers to the extent to which an intervention is faithful to its underlying theoretical and clinical guidelines (Parham et al 2007). Therefore, it is important to examine therapist fidelity to the package as well as the influence of different variables on behavioural outcomes. Examples of the latter are the duration of the package, the combination of different treatment components, specific factors related to the knowledge and skills of the research therapists, the educational levels and cultural background of the parents, and factors associated with school and teachers such as the teaching style of the teacher.

As most effective outcomes were achieved at home, it would be difficult to come to a firm conclusion about the efficacy of the package within the school environment. Consequently, it is important to strengthen the types of input that can be provided to schools if a larger-scale randomised controlled trial is to be carried out. For example, a structured training programme for school staff could be developed in order to promote a better understanding of children with ADHD, as could a whole-school approach in supporting and managing children with ADHD. It might also be helpful to extend the duration of the care package in order to provide more regular support to the class teacher, although this carries resource implications.

Another limitation of the present study was the lack of information about the long-lasting effects of the package. This could be overcome by reassessing this cohort of 20 children after 6 and 12 months to establish whether improvements are maintained. However, it may be difficult to measure the child's behavioural status in school, or to relate this to the intervention, because there are likely to be changes in staffing and the learning environment over longer periods. Therefore, perhaps longer-term follow-up should be carried out in the home environment, focusing on parental perceptions of the child's behaviour and also direct observation of the child.

\section{Conclusion}

This study has established the value of the delineation model of occupational therapy practice for children with ADHD by examining the effectiveness of an assessment and treatment package based on the model. The results are encouraging and comparable to other efficacy studies. The package encouraged the occupational therapists to recognise the vital role of parents in the therapeutic process, to increase their understanding of the parent-child interaction and to expand their skills to include effective collaboration with parents for the benefit of the child. However, further work needs to be done to understand the reported differences in the results between home and school in order to facilitate better teacher-therapist collaboration regarding the management of children with ADHD.

It is important to note that caution should be exercised in generalising the results because of the small sample size, the lack of randomisation, the absence of a control group in the research design and the potential experimenter effects on the part of the research therapists. As there are many questions left unanswered, a larger-scale randomised controlled trial should be carried out to evaluate the efficacy of an improved care package, with inputs from research therapists and parents.

Although there were various limitations, this study should be viewed as a significant initial step in the continuing development and validation of a multifaceted model of occupational therapy practice for children with ADHD. Since a model of practice represents the most dynamic arena of knowledge development in the profession, constant change is to be expected and valued. The information generated in this study will be used to refine and modify the theoretical constructs of the model and the structure and content of the intervention package.

\section{Acknowledgements}

The first author would like to thank the College of Occupational Therapists in awarding the Byers Memorial Fund and also the Hospital Saving Association in awarding the PhD Scholarship Award 2001 for his doctoral study at the School of Health Sciences and Social Care, Brunel University.

\section{References}

American Psychiatric Association (1994) Diagnostic and statistical manual of mental disorder, 4th ed. Washington, DC: APA.

Carlson CL, Shin M, Booth J (1999) The case for DSM-IV subtypes in ADHD. Mental Retardation and Developmental Disabilities Research Reviews, 5(3), 199-206.

Christiansen AS (2000) Persisting motor control problems in 11- to 12-year-old boys with deficits in attention, motor control and perception (DAMP). Developmental Medicine and Child Neurology, 42(1), 4-7. 
Chu S (2005) Developing a model of occupational therapy practice for children with attention deficit hyperactivity disorder (ADHD). Unpublished PhD thesis. Uxbridge, Middx: School of Health Sciences and Social Care, Brunel University.

Chu S, Reynolds F (2007) Occupational therapy for children with attention deficit hyperactivity disorder (ADHD), part 1: a delineation model of practice. British Journal of Occupational Therapy, 70(9), 372-83.

College of Occupational Therapists (2003) Consent for occupational therapy. London: COT.

Department of Health (2001) Seeking consent: working with children. London: $\mathrm{DH}$.

Dunn W (1999) Sensory Profile - user's manual. San Antonio, TX: Psychological Corporation.

Dunn W, Bennett D (2002) Patterns of sensory processing in children with attention deficit hyperactivity disorder. Occupational Therapy Journal of Research, 22(1), 4-15.

DuPaul GJ, Barkley RA (1993) Behavioural contributions to pharmacology: the utility of behavioural methodology in medication treatment of children with ADHD. Behaviour Therapy, 24, 47-65.

DuPaul GJ, Power TJ, Anastopoulos AD, Reid R (1998) ADHD Rating Scale - IV. New York: Guilford Press.

Giles DC (2002) Advanced research methods in psychology. Hove: Routledge.

Gillberg C, Kadesjo B (2000) Attention-deficit/hyperactivity disorder and developmental coordination disorder. In: TE Brown, ed. Attention-deficit disorders and comorbidities in children, adolescents, and adults. Washington, DC: American Psychiatric Press.

Goldstein S, Goldstein M (1998) Managing ADHD in children: a guide for practitioners. New York: John Wiley.

Gomez R, Harvey J, Quick C, Scharer I, Harris G (1999) DSM-IV AD/HD: Confirmatory factor models, prevalence and gender and age difference based on parent and teacher ratings of Australian primary school children. Journal of Child Psychology and Psychiatry, 40(2), 265-74.

Harvey WJ, Reid G (1997) Motor performance of children with attention deficit hyperactivity disorder: a preliminary investigation. Adapted Physical Activity Quarterly, 14(3), 189-202.

Jacobsen NS, Truax P (1991) Clinical significance: a statistical approach to defining meaningful change in psychotherapy. Journal of Consulting and Clinical Psychology, 59(1), 12-19.

Jensen PS (1999) Fact versus fancy concerning the multimodal treatment study for ADHD. Canadian Journal of Psychiatry, 44(10), 975-80.

Johnson RC, Rosen LA (2000) Sports behavior of ADHD children. Journal of Attention Disorder, 4(3), 150-60.

Jouglin C, Zwi M (1999) FOCUS on the use of stimulants in children with ADHD. Primary evidence-base briefing no. 1. Focus Project. London: Royal College of Psychiatrists' Research Unit.

King S, Rosenbaum P, King G (1995) The Measure of Processes of Care (MPOC): a means to assess family-centred behaviours of health care providers. Hamilton, ON: McMaster University.

King S, Rosenbaum P, King G (1998) The Measure of Processes of Care 20-item version (MPOC-20). Hamilton, ON: McMaster University.
King S, King G, Rosenbaum P (2004) Evaluating health service delivery to children with chronic conditions and their families: development of a refined Measure of Processes of Care (MPOC-20). Children's Health Care, 33(1), 35-57.

Klein R, Abikoff H, Hechtman L, Weiss G (2004) Design and rationale of controlled study of long-term Methylphenidate and multimodal psychosocial treatment in children with ADHD. Journal of American Academy of Child and Adolescent Psychiatry, 43(7), 792-801.

Mangeot SD, Miller LJ, McIntosh DN, McGrath-Clarke J, Hagerman RJ, Goldson E (2001) Sensory modulation dysfunction in children with attention-deficit/hyperactivity disorder. Developmental Medicine and Child Neurology, 43, 399-406.

Milich R, Balentine AC, Lynam DR (2001) ADHD Combined Type and ADHD Predominantly Inattentive Type are distinct and unrelated disorders. Clinical Psychology: Science and Practice, 8(4), 463-88.

MTA Cooperative Group (1999) A 14-month randomised clinical trial of treatment strategies for ADHD. Archives of General Psychiatry, 56(12), 1073-86.

National Institute for Clinical Excellence (2000) Technology Appraisal Guidance No.13 - Guidance on the use of Methylphenidate (Ritalin, Equasym) for attention deficit hyperactivity disorder (ADHD) in childhood. London: NICE.

Parham LD, Cohn ES, Spitzer S, Koomar JA, Miller LJ, Burke JP, Brett-Green B, Mailloux Z, May-Benson TA, Smith-Roley S, Schaaf RC, Schoen SA, Summers CA (2007) Fidelity in sensory integration intervention research. American Journal of Occupational Therapy, 61(2), 216-27.

Piek JP, Pitcher TM, Hay DA (1999) Motor coordination and kinaesthesis in boys with ADHD. Developmental Medicine and Child Neurology, 41(3), 159-65.

Pitcher TM, Piek JP, Hay DA (2003) Fine and gross motor ability in males with ADHD. Developmental Medicine and Child Neurology, 45(8), 525-35.

Shelton T, Jeppson E, Johnson B (1987) Family centered care for children with special health care needs. Washington, DC: Association for the Care of Children's Health.

Spencer T, Biederman J, Wilens T, Harding M, O'Donnell D, Griffin S (1996) Pharmacotherapy of attention deficit hyperactivity disorder across the life cycle. Journal of American Academy of Child and Adolescent Psychiatry, 35(4), 409-32.

Taylor E, Hemsley R (1995) Treating hyperkinetic disorders in children. British Medical Journal, 310, 1617-18.

Tseng MH, Henderson A, Chow SMK, Yao G (2004) Relationship between motor proficiency, attention, impulse, and activity in children with ADHD. Developmental Medicine and Child Neurology, 46(6), 383-88.

Whitmont S, Clark C (1996) Kinaesthetic acuity and fine motor skills in children with ADHD: a preliminary report. Developmental Medicine and Child Neurology, 38(12), 1091-98.

Wodrich DL (1994) ADHD - what every parent wants to know. Baltimore: Paul H Brookes Publishing. 